\title{
Proceedings of the first meeting of the Operational Research (OR) Society's Special Interest Group on Agriculture and Natural Resources (SIG-ANR)
}

\author{
EDITED BY
}

\section{L. SANDARS}

School of Applied Science, Cranfield University, Cranfield, MK43 OAL, UK

This group, which represents the reformed Operational Research (OR) Society's Agriculture and Related Industries group (http://www.orsoc.org.uk), promotes the use of OR (or the application of the scientific method) in solving management and governance problems within this sector. The theme of this meeting was to look at models concerned with making better decisions for the management or governance of the agricultural and natural resource industries. This first one day meeting was at Reading University, Berkshire, UK on the 2nd April when the following papers were read.

\footnotetext{
Material on these pages is copyright Cambridge University Press or reproduced with permission from other copyright owners. It may be downloaded and printed for personal reference, but not otherwise copied, altered in any way or transmitted to others (unless explicitly stated otherwise) without the written permission of Cambridge University Press. Hypertext links to other Web locations are for the convenience of users and do not constitute any endorsement or authorisation by Cambridge University Press.
} 
Developing managerial decision aids from efficiency analysis. M. E. BREDAHL AND S. SAMARAJEEWA. Centre for Agribusiness Research and Management, 224 MacLachlan Hall, University of Guelph, Guelph, ON N1G 2W1, Canada

Estimation of the technical efficiency of agricultural production processes, using techniques such as stochastic frontier analysis and data envelopment analysis, is commonplace in the agricultural economics literature (Farrell 1957). Typically, the average levels of technical and allocative efficiency, and, as a second stage, estimates of factors contributing to the level of efficiency are reported. Most often these factors are related to policy variables, such as access to rural credit markets, but have not been related to managerial decision aids. This paper reports an attempt to relate the outcomes of the second stage estimates of determining factors to key performance indicators. Identification and estimation of key performance indicators (KPIs) is a promising new area of management science. These KPIs are interim measures used to judge the progress toward meeting a managerial goal, such as return on investment. They also trigger corrective action if progress toward the goal is judged to fall short of expectations.

Using data collected over a 7-year period on Alberta cow/calf production (320 total observations), a stochastic frontier was estimated and various factors identified that affected the level of efficiency. An average level of efficiency of 0.75 was estimated with significant variation across observations, and particularly for those with less than 100 cows. However, some producers with less than 100 cows were found to have very high levels of estimated technical efficiency and all larger producers were found to have high levels of technical efficiency. Three commonsense KPIs were: (1) conception rate (related to breeding practices and genetics); (2) calving rate (related to birthing practices) and (3) weaning rate (related to herd health protocols). In addition, management practices related to animal cleanliness and handling were found to be of particular importance.

This research is being extended by a managerial benchmarking programme, financed by the Ontario Agricultural Management Institute, to identify managerial practices associated with superior profitability in Ontario cow/calf operations. Once the objective is expanded to include profitability, marketing and financial management practices receive as much attention as physical production practices.

FARRELL, M. J. (1957). The measurement of productive efficiency. Journal of the Royal Statistical Society, Series A 120, 253-281. 
Vehicle routing and container scheduling in timber transport. J. ZAZGORNIK, M. GRONALT AND P. HIRSCH. Institute of Production and Logistics, University of Natural Resources and Applied Life Sciences, Vienna, Feistmantelstrasse 4, 1180 Vienna, Austria

New transportation technologies need new methods for performing transport tasks efficiently. In this study foldable containers are used to transport forest products from forests to industrial sites and further on to customers. Nowadays, in forest and timber industries, containers are mostly used for transporting finished or semi-finished wood products from sawmills to customers but very seldom for round logs from forest to saw or paper mills, or for chips from forest to energy plants. It is assumed that one container could be used for transporting several different wood products (e.g. round logs, sawn lumber, chips). As far as we know the possibility of using foldable and stackable containers in wood transport has not yet been described in the literature. There is a need to develop a mathematical model formulation for this problem and evaluate possible methods for solving this kind of vehicle routing problem. For related literature on timber transport see, e.g. Palmgren et al. (2004), Gronalt \& Hirsch (2007), Bredström \& Rönnqvist (2007), and Flisberg et al. (2009).

The aim of the current study is to develop a vehicle routing and container scheduling system to determine the number of containers at each place and how to move them between different locations to perform all necessary transport tasks. Therefore the Foldable Container Scheduling Problem (FCSP) was defined. The FCSP can be seen as a variant of the well-known Vehicle Routing Problem (VRP) (see e.g. Gronalt \& Hirsch 2007) and was formulated as a Mixed Integer Programming Model. In the FCSP a given set of transport tasks has to be performed by a fleet of homogeneous trucks while meeting a time deadline, maximum tour length and precedence constraints, and with the objective of minimizing total empty travel time. All transport tasks are known in advance for each planning period.

Larger problems are solved by using a modified nearest neighbour insertion heuristic and improved by a metaheuristic called dynamic Tabu Search with Alternating Strategy (TSAS). It is based on static TSAS, which was developed for solving the Timber Transport Vehicle Routing Problem (Gronalt \& Hirsch 2007) and motivated by Granular Tabu Search (Toth \& Vigo 2003). Static TSAS leads to drastic reduction of computing times compared to Tabu Search, by no or only minimal losses in solution quality (Gronalt \& Hirsch 2007). Dynamic TSAS means changing neighbourhoods dynamically after a predefined number of iterations without improvement. Numerical studies were performed to validate the presented algorithms.

BREDSTRÖM, D. \& RönNQVist, M. (2007). Combined Vehicle Routing and Scheduling with temporal precedence and synchronisation constraints. European Journal of Operational Research 191, 19-31.

FLISBERG, P., LIDEN, B. \& RÖNNQVIST, M. (2009). A hybrid method based on linear programming and tabu search for routing of logging trucks. Computers \& Operations Research 36, 1122-1144.

Gronalt, M. \& Hirsch, P. (2007). Log-Truck Scheduling with a Tabu Search strategy. In: Metaheuristics - Progress in Complex Systems Optimization (Eds K. F. Doerner, M. Gendreau, P. Greistorfer, W.J. Gutjahr, R.F. Hartl \& M. Reimann), pp. 65-88. New York, USA: Springer. 
PALMgRen, M., RÖNNQVIST, M. \& VÄRBRAND, P. (2004). A near-exact method for solving the log truck scheduling problem. International Transactions in Operational Research 11, 447-464.

Toth, P. \& Vigo, D. (2003). The Granular Tabu Search and its application to the Vehicle Routing Problem. INFORMS Journal on Computing 15, 333-346. 
Land consolidation by means of Integer Linear Programming. S. BORGWARDT $^{1}$, A. BRIEDEN ${ }^{2}$, AND P. GRITZMANN ${ }^{1}{ }^{1}$ Technische Universität München, Germany, ${ }^{2}$ Universität der Bundeswehr München, Germany

In many farming areas in various countries of the world, farmers cultivate a large number of small-sized lots that are scattered over an extended agricultural area. First, since the single separate lots are rather small, modern heavy machinery cannot be used profitably. Hence, the cost of cultivation is much higher than it would be for fewer, larger lots of the same total size. Second, since the individual lots are scattered over a large region, there is considerable 'overhead driving', resulting in an excess of work force and transportation costs.

In its classical form, land consolidation consists of a complete restructuring of the agricultural area, discarding the current and creating a new lot structure. This process involves extended surveying and new legal assignments of property, and hence is costly, lengthy and inflexible. Typically, once decided on, farmers are obliged to participate in this process. Another disadvantage surfaces in agricultural areas where the majority of lots is in fact cultivated by farmers other than the lot owners through land-lease agreements, hence a scattered agricultural structure is predominant even in regions that have undergone a classical form of consolidation in the recent past. On the other hand, a farmer who cultivates a lot rented from some other owner is generally less tied to the lot, and is hence more willing to 'trade' it. This opens the possibility of improving the cost structure of agricultural production through conceptually simple exchange of land-lease agreements based on the existing lot structure.

For optimally redistributing existing lots among the participating farmers two different objectives are relevant. First, large fields are desirable, and second, the connected lots of a farmer should be close to each other. Naturally, the total size of each farmer's land should not change much in the course of redistribution; neither should its value or other possibly relevant parameters. Of course, farmers must be allowed to fix some of their lots and leave only the other lots subject to redistribution. The model for this problem is described in detail in Borgwardt et al. (2009) and is based on Integer Linear Programming, which leads to a flexible and efficient algorithm that performs favourably with respect to all relevant economic objective functions given by the Bavarian State Institute for Agriculture.

Borgwardt, S., Brieden, A., \& Gritzmann, P. (2009). Constrained Minimum-kStar Clustering and its Application to the Consolidation of Farmland, Operational Research - An International Journal - Special Issue: Optimization in agriculture. DOI 10.1007/s12351-009-0041-y

(http://www.springerlink.com/content/015520844km8666j/) 
Life cycle assessment of environmental impacts of UK pig production systems K. L. STEPHEN, B. J. TOLKAMP, C. F. E. TOPP AND J. G. M. HOUDIJK. SAC, Kings Buildings, West Mains Road, Edinburgh, EH9 3JT, UK

The UK pig industry is seeking viable methods to reduce its environmental impacts. One area where environmental improvements may be achieved is in pig nutrition, especially in the sourcing of pig diet ingredients. The UK relies heavily on imported feedstuffs, primarily soybean meal, from countries such as Brazil. Long distance transportation increases the energy demands of the system and can lead to mineral excess locally.

Using Life Cycle Assessment (LCA) methodology, predictions were made of the environmental impacts of replacing soybean meal with home-grown protein sources in pig diets designed to supply all the nutritional requirements of growing pigs. All processes in the production system were included in the LCA. Two dynamic and deterministic models have been combined to assess the environmental consequences of using home-grown protein sources in pig diets. The DeNitrificationDeComposition (DNDC version 93) (Li 2007) model was used to simulate the growth of all crops used in the pig diets. DNDC simulated the yields and greenhouse gas emissions for crops in the rotation spring barley - winter barley winter rapeseed - winter wheat - spring protein crop. Simulations were carried out for two UK regions, each with its specific soil type. Simulations were run for 10 years with site-specific climatic conditions. The global warming potential (GWP) per $\mathrm{kg}$ of grain crop ranged from $0.65-0.85 \mathrm{~kg} \mathrm{CO}_{2}$ Equivalent $^{100}$ in East Anglia and from 0.85-1.2 $\mathrm{kg} \mathrm{CO}_{2}$ Equivalent $^{100}$ for the same rotation grown in York. The same simulations were carried out for rotations in which beans were replaced with either peas or lupins.

The crops resulting from the DNDC modelling were used to formulate pig diets that were fed into a pig growth model (Wellock et al. 2004) that was used to simulate pig growth from $12-106 \mathrm{~kg}$, based on precise estimates of nutritional requirements. The total GWP per kg produced pig meat, including all contributions, varied with diets, area and climatic conditions from 1.75-2.01 and from $1.89-2.26 \mathrm{~kg}$ $\mathrm{CO}_{2}$ Equivalent ${ }^{100}$ for East Anglia and Yorkshire, respectively, for bean-based diets. Overall, between 0.88 and 0.91 of the GWP/kg meat was due to crop production.

We conclude that a large proportion of the variation in GWP associated with pig production systems is related to variation in the growing conditions (in terms of soils and climate) of crops used in pig diets. Life Cycle Assessment is a very useful methodology to assess such variation.

Wellock, I., EMmANS, G. \& KYRIAZAKIS, I. (2004). Describing and predicting potential growths in pigs. Journal of Animal Science 78, 379-388.

LI, S. (2007). Quantifying greenhouse gas emissions from soils: Scientific basis and modelling approach. Soil Science and Plant Nutrition 53, 344-352 
Network models for the spread of plant disease in trade pathways. $M$. PAUTASSO AND M. J. JEGER, Division of Biology, Imperial College London, Silwood Park, Ascot, SL5 7PY, UK

Networks, sets of nodes connected in various ways by links, are ubiquitous in nature and widely used in science. Network models are of increasing relevance for plant health due to the growing horticultural trade within and among countries. Many recent studies have focused on epidemics in large-scale complex networks (Jeger et al. 2007). Whether or not findings of these models also apply to networks of small size is still an open question. Networks of small size are of relevance for the horticultural trade and for a number of other biological applications (e.g. food webs, metapopulations, metabolic networks). Models have been developed simulating the spread of plant pathogens through the movement of diseased plants in the nursery trade (Pautasso \& Jeger 2008). The model structure was based on small-size directed graphs of different topologies (local, small-world, random, scale-free) with two simple parameters: the probabilities of disease transmission among connected nodes and disease persistence at nodes. The epidemic threshold is significantly lower for scale-free networks compared to local, random and small-world ones only if superconnected nodes have a higher number of links both to and from other nodes. The starting point does not affect the threshold conditions, but influences the final size of the epidemic in all kinds of network. The results confirm also for small-size networks that disease control would be more efficient and effective if knowledge of the underlying trade network were available. For the UK, the contact structure of the horticultural trade is poorly characterized owing to commercial sensitivity. We carried out a separate spatial analysis of the aggregation of the reported cases of Phytophthora ramorum (the oomycete causing Sudden Oak Death in the West Coast of the USA and leaf blight and dieback in ornamental shrubs in Europe) on hardy nursery stock in both UK nurseries and the semi-natural environment (Xu et al., in press). This analysis suggests that statutory actions taken so far are likely to have reduced the long-distance spread of $P$. ramorum among garden centres and nurseries. However, $P$. ramorum persists in the semi-natural environment, particularly in Southwest England, with continuing risk of re-infection of the horticultural trade.

JEGER, M. J., PAUTASSO, M., HOLDENRIEDER, O. \& SHAW, M. W. (2007). Modelling disease spread and control in networks: implications for plant sciences. New Phytologist 174, 279-297.

PAUTASSO, M. \& JEGER M. J. (2008). Epidemic threshold and network structure: the interplay of probability of transmission and of persistence in small-size directed networks. Ecological Complexity 5, 1-8.

XU, X. M., HARWOOD, T. D., PAUTASSO, M. \& JEGER, M. J. (in press) Spatiotemporal analysis of Phytophthora ramorum cases in UK (2003-2006). Ecography. 32, 504-516. 